\title{
The Research on the Effect of Consumer Internal Psychological Preference to the Retail Industry Inventory
}

\author{
Lina Fang, Yu Hou, Yangchen Chen \\ Business Administration, University of Science and Technology Liaoning, Anshan, China \\ Email: asfanglina@163.com
}

How to cite this paper: Fang, L.N., Hou, Y. and Chen, Y.C. (2016) The Research on the Effect of Consumer Internal Psychological Preference to the Retail Industry Inventory. Journal of Service Science and Management, 9, 398-408.

http://dx.doi.org/10.4236/jssm.2016.95044

Received: May 11, 2016

Accepted: October 11, 2016

Published: October 14, 2016

Copyright $\odot 2016$ by authors and Scientific Research Publishing Inc. This work is licensed under the Creative Commons Attribution International License (CC BY 4.0).

http://creativecommons.org/licenses/by/4.0/

\begin{abstract}
Supply chain inventory plays an increasingly important role in rising prosperity and flexible retail industry. The retail industry's own characteristics determine the importance of the inventory. The inventory management has played an important role in reducing the cost of supply chain and the whole supply chain coordination and stability. This paper takes the consumer internal psychological preference as the starting point. Data are obtained through market research on consumer internal psychological preference and consumer sensitivity of the inventory. Based on the internal psychological preferences of consumers, the correlation among product quality, product price, and consumer behavior of the three potential variables is analyzed. This paper constructs the structural equation model of consumer behavior and inventory sensitivity, and puts forward the main issues and improvement measures to the retail industry inventory.
\end{abstract}

\section{Keywords}

Consumer, Psychological Preference, Retail Industry Inventory

\section{Introduction}

In recent years, with the continuous development of economy, people's living standards continue to improve; the purchase of retail products frequently increases; and the competition among retailers is also growing. To provide customers with high quality service and low price of high quality products becomes more and more important in the competition of retail enterprises. But at the same time, reducing internal management costs has become the key of retail enterprise internal management. The procurement costs, purchase costs and quality costs all have an intimate relationship with in- 
ventory management [1]. On the one hand, strengthening internal inventory management of retail enterprise reduces management costs, avoiding the dilemma of "profits are eaten by warehouse". On the other hand, it can be able to meet consumers demand for the product, and ensure the long-term development of the retail enterprise.

Strengthening the coordination of every node enterprise in supply chain is the focus of many scholars study. VIM (Vendor Inventory Management), JMI (Jointly Managed Inventory) and CPFR (Collaborative Planning, Forecasting and Replenishment) are all advanced and effective methods of inventory management. JMI emphasizes the participation of each node in the supply chain, so that each inventory management in the supply chain can be considered from the coordination. CPFR focuses on the mutual cooperation between the other management and inventory management [2]. These management methods are all solved the problem of the inventory from the perspective of supply chain management. In recent years, some scholars have studied from different angles on the supply chain inventory management. Vishal Gaur (2003) through the 1987 to 2000 survey of 311 retail companies found that the price of product, the type of product and the life cycle of product have a huge impact on product inventory [3]. Therefore, we should take some measures for the different characteristics of different inventory products, so that we can accurately grasp the market demand, and improve the response rate to reduce the number of products not sold.

The above research shows the supply chain inventory management from the point of each node of supply chain and product characteristics. But at the same time, consumer's behavior and demand as well as the most important factors affect retail enterprise inventories. This paper takes the consumer internal psychological preference as the starting point, exploring its impact on the retail enterprise inventories from the perspective of consumer behavior, by accurately grasping the consumer demand to supply products.

\section{Research Model}

\subsection{Analysis of Consumer Internal Psychological Preference}

Kollat (1968) consider consumer behavior composed of consumers' purchase decision and purchase action [4]. Purchase decision is the process of the formation of consumer attitudes, which is a psychological activity and behavior tendency to the products you want to buy. Purchases action is the implementation process of consumer purchase decisions. Purchasing decisions caused the action of purchase, and the effect of purchases also have an impact on the next purchase decision, both mutual penetration and influence. Lilien (1992) dividing the process of consumer purchase decision into five stages, there are need recognition, information search, evaluation of alternatives, purchase decision, and post-purchase behavior [5]. Habits, needs motivation, inner conviction, purchase intent, evaluation and other factors will have an impact on purchasing decisions and the following buying behavior. This paper mainly studies the subjective factors that affect consumer behavior, which is primarily associated with consumers motivation, attitude, perception and other factors. These factors have an influence on 
consumer purchase decision, so it will change consumers' behavior.

\subsection{The Problems of Inventory Management That Exist in the Retail Industry}

\subsubsection{Poor Coordination between the Internal Departments of Enterprise}

In our country's retail enterprises, purchasing department, sales department, and inventory management department have less internal communication and coordination, which lead to the phenomenon that procurement and sales out of touch. Purchasing departments cannot understand the needs of the market at the first time, the sales department cannot well understand the inventory of the products to develop targeted marketing plan, and the inventory management department can't timely and effective oversight the purchasing products.

\subsubsection{The Situation of Shortage of Products Is Common}

Shortages were divided into two types, one is the enterprise did not have the product that consumers demand, and the other one is inventory have no sufficient products. Both cases are generated from the underestimated to consumer demand. And facing to the situation of shortage, only thirty percent of consumers will choose to buy alternatives, most consumers will choose to buy it in the other place. Therefore, the shortage problem is the major problem of inventory management that existing in the retail enterprise.

\subsubsection{Inventory Backlog Serious}

The unsold products lead to the inventory backlog. Product price is too high, have no competitive advantage in similar products, product display position is not perfect caused consumer's attention shifted, and out-of-season products are not taking away in time, both of them are all the reason of unsold. As the same of shortage, the underestimated to consumer demand is the main reason of inventory backlog.

\subsection{The Selection of Indicators and the Building of the Model}

The theoretical model of this study is shown in Figure 1, the consumer quality preference, consumer price preference, and consumer convenient-service preference are external latent variables, consumer inventory sensitivity is internal latent variable. In the dimension of consumer quality preference include four measured variables that describe its characteristics. In the dimension of consumer price preference include four measured variables that describe its characteristics. In the dimension of consumer convenient-service preference include seven measured variables that describe its characteristic.

\section{Collection and Collation of the Model's Data}

\subsection{The Design of the Questionnaire}

This study aimed at consumers' internal psychological preferences, using a questionnaire to quantify the data. Converting abstraction of mental preference index into 


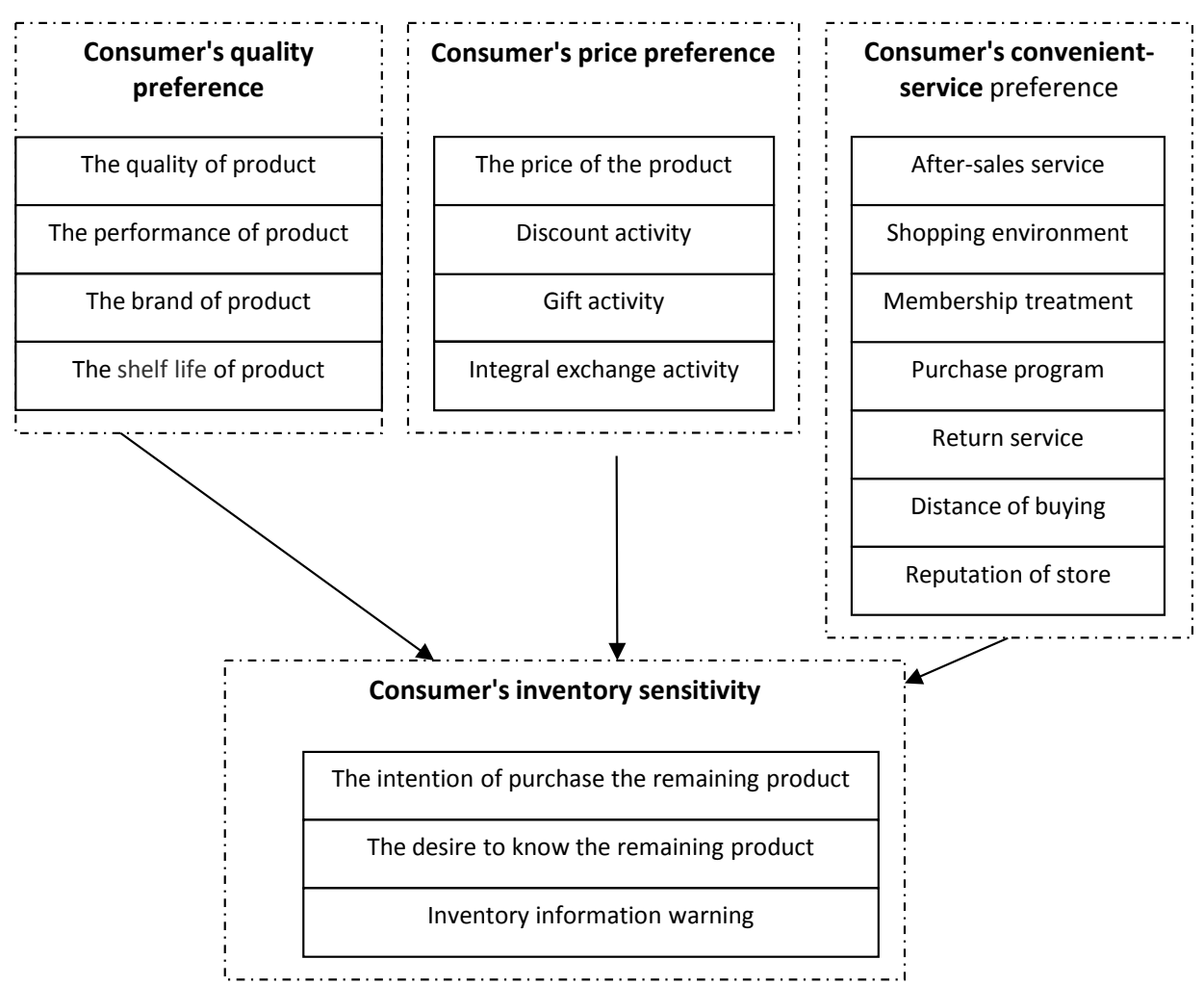

Figure 1. The theory model of relationship between consumer internal psychological preference and inventory sensitivity.

popular intuitive to measure psychological preferences of consumers. As shown in Table 1 , the questionnaire is divided into three parts, the first part is the basic information of consumers, which qualified the basic situation of the investigator, in order to ensure the reasonableness of the questionnaire. The second part is the specific measurement items of exogenous variables. The third part is the measurement items of internal variables. According to the difference of preference degree, using Liken five scale to quantify the index from 1 - 5. In the process of questionnaire setting to fully consider the integrity, semantic precision and logic.

\subsection{Data Collection}

Distributing the questionnaire in the 5 District of Anshan city in Liaoning Province with the method of random sampling. Reference statistical relevant principles, requires of the questionnaire and the limit number of questionnaire. Filling in each questionnaire for 10 to 15 minutes [6], grant 400 questionnaires and 386 shares of effective questionnaire altogether, the rate of the effective questionnaire is $96.5 \%$.

\subsection{The Analysis of Reliability and Validity}

Analysis of reliability and validity of the model is a necessary step to test the accuracy of the model. In this paper, analysis of reliability and validity mainly include: first of all, analyzing overall reliability of the scale and removing the item which is not conform to 
the standard, preliminary purification of the scale. Then, followed by the exploratory factor analysis with the method of principal component analysis, and eliminating the item that have Structural problems. Finally, analyze reliability of each structure variables respectively, and further optimized the scale.

\subsubsection{The Integral Reliability Analysis of the Model}

Reliability is the analysis and test of stability and credibility of the data. Cronbach's Alpha reliability coefficient is mainly used to analyze the internal reliability of the model, using the variance, the covariance matrix and the correlation matrix of items calculate the internal consistency reliability coefficient, which is one of the most commonly methods of reliability analysis [7]. This paper use the SPSS_21.0 to analyze CITC (Corrected Item Total Correlation) and Cronbach's Alpha coefficient of the model. The reliability level is perfect when Cronbach's Alpha coefficient is greater than 0.7 and it is better when the reliability level is 0.65 to 0.7 .

As it shown in Table 2, by the analysis of SPSS_21.0, the integral reliability coefficient of the questionnaire was 0.686 , which is greater than 0.65 but less than 0.7 . In order to further improve the integral reliability of the model, eliminating the item that CITC $<0.4$ and Cronbach's Alpha coefficient will increase when it is deleted. The items of the shelf of products and the distance of buying were deleted.

Table 1. Measurement items of consumer internal psychological preference and the inventory sensitivity in retail industry.

\begin{tabular}{cl}
\hline \multicolumn{1}{c}{ Dimension } & \multicolumn{1}{c}{ Questionnaire items } \\
\hline The basic information & (1) Gender \\
(A) & (2) Age
\end{tabular}


After removing the items, the overall reliability of the questionnaire was 0.716 , greater than 0.7 (shown in Table 3). The integral reliability of the model is better, the remaining items of the questionnaire is stability and unity, and the next step is the factor analysis, which is about Structure validity.

\subsubsection{The Validity Analysis of the Model}

This paper use SPSS_21.0 conduct Barlett Test of Sphericity and KMO test. The KMO coefficient was 0.605 greater than 0.5 and sig. $=0.00$, suitable for the analysis of principal component factor. Extracting 3 main factors in the remaining variables with the method of principal component analysis (Table 4). Compared the extracted main factor with the main factor of designing in questionnaire, there are almost the same, and delete the inconsistent items. To further improve the structure validity of the questionnaire, the items of products price, shopping environment, membership treatment and the reputation of store were deleted.

Table 2. Cronbach's alpha coefficient of the model.

$$
\text { Cronbach's alpha The number of item }
$$

$\begin{array}{ll}0.686 & 18\end{array}$

Table 3. Optimized Cronbach's alpha coefficient of the model.

Cronbach's alpha The number of item

0.716

16

Table 4. Component matrix of exploratory factor analysis.

\begin{tabular}{cccc}
\hline & & Component & 3 \\
\cline { 2 - 3 } Item & 1 & 2 & \\
\hline Performance of product & 0.722 & & \\
Shopping environment & 0.714 & & \\
Quality of product & 0.657 & & \\
Reputation of store & 0.593 & 0.826 & \\
Brand of products & 0.577 & 0.731 & 0.798 \\
Gift activity & & 0.704 & 0.506 \\
Integral exchange activity & & 0.509 & 0.476 \\
Discount activity & & & \\
Membership treatment & & & \\
Price of product & & & \\
After-sales service & & & \\
Return service & & & \\
Purchase program & & & \\
\hline
\end{tabular}


After deleting 4 items, as it shown in Table 5, using SPSS_21.0 conduct Barlett test and $\mathrm{KMO}$ test. The KMO coefficient was 0.617 greater than 0.5 and sig. $=0.00$. Exploratory factor analysis to finalize the three main components (shown in Table 6), there are Consumer quality preference, Consumer price preference and Consumer convenient-service preference. Component preserves more information of the original data, and the factor loading of principal component are all greater then 0.5 , the results of principal component factor analysis can be accepted [8].

\subsubsection{The Reliability Analysis of the Structure Variable}

After the validity analysis of the model, the result of integral reliability analysis of the model is shown in Table 7 , greater then 0.65 , and the overall reliability of the model is better. The result of the structure variable reliability analysis is shown in Table 8, the Cronbach's Alpha coefficient of Consumer convenient-service is less than 0.65. To further improve the reliability of the questionnaire, the structure variable of consumer convenient-service were deleted.

Table 5. Optimized Barlett test and KMO test.

\begin{tabular}{lcc}
\hline \multicolumn{2}{c}{ Kaiser-Meyer-Olkin } & 0.617 \\
\hline \multicolumn{3}{c}{ Chi squared approximation } \\
Barlett test of sphericity & df. & 130.296 \\
& Sig. & 36 \\
\hline
\end{tabular}

Table 6. Optimized component matrix of exploratory factor analysis.

\begin{tabular}{cccc}
\hline & \multicolumn{3}{c}{ Component } \\
\cline { 2 - 4 } Item & 1 & 2 & 3 \\
\hline Quality of product & 0.861 & & \\
Performance of product & 0.777 & & \\
Brand of products & 0.630 & 0.822 & \\
Gift activity & & 0.785 & 0.751 \\
Integral exchange activity & & 0.745 & 0.700 \\
Discount activity & & & 0.538 \\
Purchase program & & & \\
Return service & & & \\
After-sales service & & & \\
& & & \\
\hline
\end{tabular}

Table 7. The optimized Cronbach's alpha coefficient of the model.

Cronbach's alpha

0.699
The number of item

12 


\section{The Analysis of the Structural Equation Model}

\subsection{The Construction of Structural Equation Model}

There are 3 latent variables in the structural equation model, the latent variables are consumer quality preference, consumer price preference and consumer inventory sensitivity. Consumer quality preference and consumer price preference are external latent variables, and consumer inventory sensitivity is internal latent variable. This study use AMOS17.0 to analyze the relationship and influence degree of the latent variable in the structural equation model. Figure 2 shows the results of the analysis.

\subsection{Confirmatory Analysis of Structural Equation Model}

\subsubsection{Evaluation of Structural Equation Models}

The ratio of Chi-square with degrees of freedom $\left(\chi^{2} / \mathrm{df}\right)$ is a statistic which is test the degree of similarity between sample covariance matrix and the estimated covariance matrix directly, which is the fitting degree between the model and data, less than 2 for the best [9]. GIF (Goodness of Fit Index) and AGIF (Adjust Goodness of Fit Index) is the index that is used for testing the goodness of fit of the model. RMR (Root Mean

Table 8. The optimized Cronbach's alpha coefficient of the structure variable.

\begin{tabular}{ccc}
\hline Structure variable & Cronbach's alpha & The number of item \\
\hline Consumer's quality preference & 0.667 & 3 \\
\hline
\end{tabular}

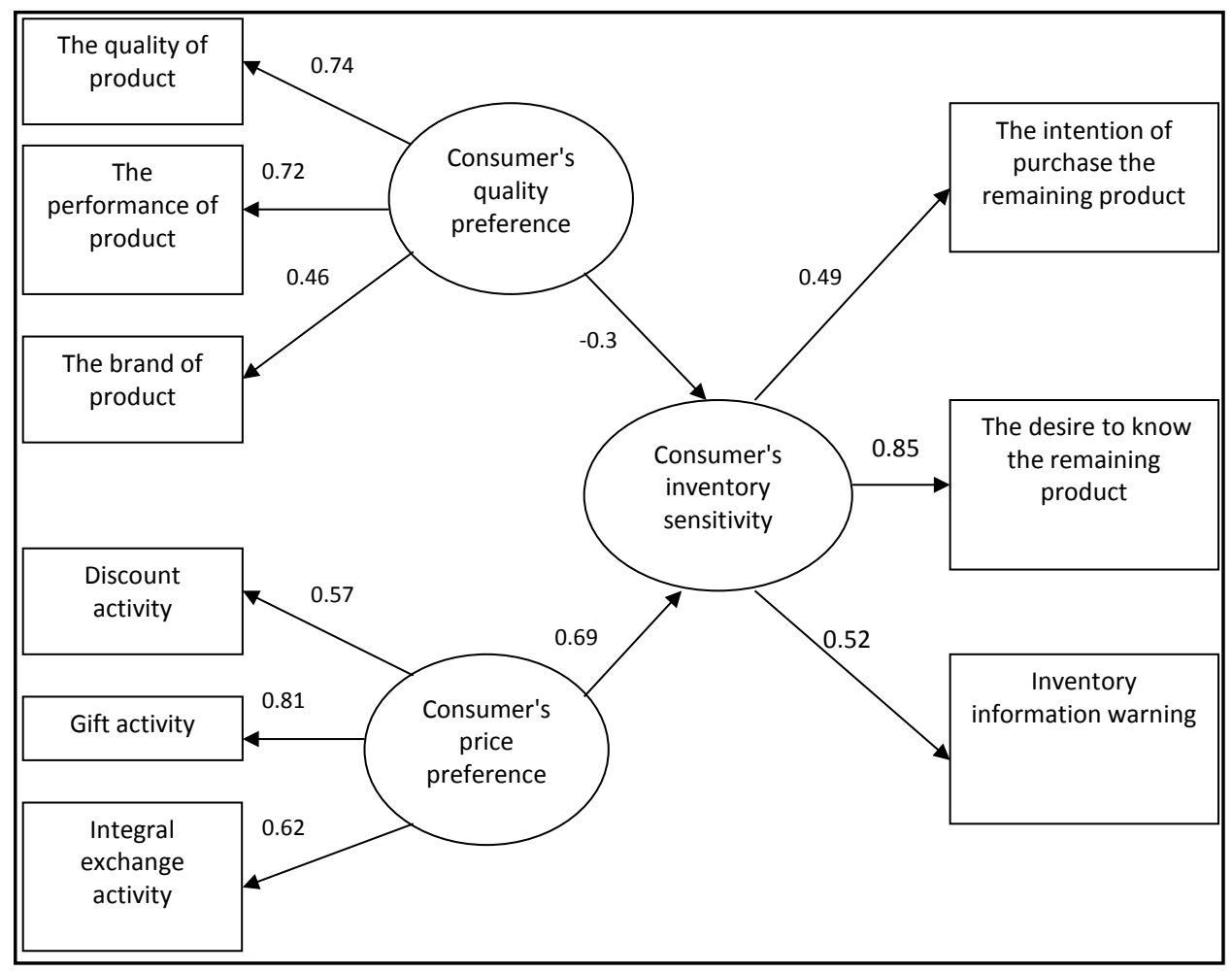

Figure 2. Structural equation model. 
Square Residual) is the integral residual of the standardization model, RMR reflect the problem of poor fitting. EMSEA (Root Mean Square Error of Approximation) is also the absolute fit index of reflecting the model fitting degree. NFI (Normed Fit Index), CFI (Comparative of Fit Index), and IFI (Incremental Fit Index) are relative fit index. As shown in Table 9, all the indexes of the model conform to the requirements of the reference, proving the fitting degree of the model is better.

\subsubsection{Inspection of the Structural Equation Model}

When the significance level of path coefficient between 0.05 and 0.1 and the absolute value of the statistic is greater than 1.65 , it means that two groups of coefficient having a significant difference. When the significance level of path coefficient between 0.005 and 0.01 and the absolute value of the statistic is greater than 2.6 , it means that two groups of coefficient having a significant difference. The result shows the significance of the model is ideal (shown in Table 10).

\subsection{The Analysis and Summary of the Structural Equation Model}

By the evaluation and significance test of the model, the structural equation model has a good fitting degree and significant. As it shown in Figure 2, in the measurement model, the measurement variables and latent variables are positive correlation, and the correlation coefficient is greater than 0.4. It shows that the measurement variables and latent variables have a high correlation. In the structural model, the correlation coefficient between consumer inventory sensitivity and consumer price preference is 0.69 ,

Table 9. Actual value of the model compared with the reference value.

\begin{tabular}{cccc}
\hline Index & Actual value & reference value \\
\hline$\chi^{2} / \mathrm{df}$ & 0.808 & $<2$ \\
GFI & 0.938 & $>0.8$ \\
Absolute fit index & AGIF & 0.884 & $>0.8$ \\
RMR & 0.046 & $<0.08$ \\
RMSEA & 0.000 & $<0.05$ \\
\hline Nelative fit index & NFI & 0.856 & $>0.8$ \\
CFI & 1.000 & $>0.9$ \\
\hline
\end{tabular}

Data source: Hou Jietai, Wen Zhonglin, Chen Zijuan. Structural equation model and its application [10].

Table 10. Result of the model test.

\begin{tabular}{ccccc}
\hline Relationships between variables & C.R. & P & The test results \\
\hline Consumer inventory sensitivity-Consumer quality preference & -1.973 & 0.082 & $\sqrt{ }$ (support) \\
Consumer inventory sensitivity-Consumer price preference & 2.774 & 0.006 & $\sqrt{ }$ (support) \\
\hline
\end{tabular}


the positive correlation is stronger. It shows that the more consumer price preference, the more inventory sensitivity. By the same token, the correlation coefficient between consumer inventory sensitivity and consumer price preference is -0.31 , the relationship of them is negative correlation.

\section{Countermeasures and Suggestions}

\subsection{Conclusion of the Analysis}

Seen from the results, the price-care consumers are more and more concerned about the product inventory, and they hope to be able to buy products for the first time. First, due to the short-term of promotional activities, consumers become more sensitive to the inventory of the discounted product. Second, changes in commodity prices have led to changes in demand. This change in demand also increased the concern of price preference consumer about remaining products. In addition, the purchase frequency of low-priced product is higher than that of the high-priced price products. Therefore, there is a greater change in low-priced products inventory. So the consumers which focus on low-priced products will pay more attention to product inventory.

The consumers of quality preference pay more attention to the quality of the products in the process of shopping, which have a higher intention of waiting and will not change the plan of purchase by the limit of inventory. All told, if consumers paid more attention to product quality rather than price and targeted to buy the product, they would not change their purchase decision and behavior easily.

\subsection{Suggestions of Inventory Management of Supply Chain in Retail Industry}

\subsubsection{Strengthen the Cooperation among Departments of Retail Enterprises}

The product demand will be huge fluctuations when product promotion, it is very difficult for procurement staff to making accurate predictions only rely on experience when the market demand is change, so the coordination of sales department and purchasing department plays an important role in effective management of product inventory. Sales department feedback the market demand condition to the purchasing department timely so that purchasing department purchases product based on demand of market. The inventory management department response the inventory information to the sales department timely so that sales department can make product pricing and promotion planning accurately. By the effective cooperation of departments can effectively reduce the cost of inventory and the situation of out of stock and unmarketable.

\subsubsection{Coordinate the Inventory Ratio of Different Kinds of Product}

Model results show that price preference consumers pay more attention to the number of remaining, which is different from quality preference consumers. So, for similar product, the inventory stock quantity of low price products should be slightly bigger than the high quality products. One of the reasons is that low-priced products have a large demand and more easily to out of stock. On the other hand, most of the consumers buying the cheap products are price preference consumers; they have a low re- 
quirement of quality and hope to get the expectation product for the first time. Therefore, enterprises should further coordinate the ratio of product in different quality and different price.

\section{Project Fund}

Liaoning Provincial Department of Education: Distinguished Young Scholars in Universities in 2013 growth plan WJQ2013006.

2015 Annual Social Science Fund Project in Liaoning Province Planning: The next big data-based service supply chain linkage development of Dalian Port and Yingkou Analysis and Research (L15BGL006).

2015 Liaoning University of Science and Technology Innovation Team Project: Internet + supply chain management innovation and decision behavior2015TD05.

National Science Foundation: population-based security awareness virtual individuals emerge (71571091).

National Science Foundation: Innovation Relay Assessment and Distribution of large data value (71472080).

National Science Foundation: Model and Empirical Research Innovation Relay: A biopharmaceutical Case (71372121).

Anshan City Bureau of Science and Technology: Research and Application of Enterprise Supplier Assessment and Performance Management System.

\section{References}

[1] Zhang, J. (2007) Study on Chain Retail Inventory Management Model of China. Southwestern University of Finance and Economics, Sichuan, 5-9.

[2] Liu, P.F. and Xie, R.H. (2006) Comparative Study on the Method of Modern Inventory Management Based on Supply Chain. Business Research, 2, 173.

[3] Gaur, V., Fisher, M.L. and Raman, A. (2003) Retail Inventory Productivity: Analysis and Bench Marketing. Management Science, 51, 181-194.

http://dx.doi.org/10.1287/mnsc. 1040.0298

[4] Engal, J.F., Kollat, D.T. and Blackwell, R.D. (1968) Consumer Behave. Holt, Rinehart and Winston, New York.

[5] Lilien, G.L., Kotler, P. and Moorthy, K.S. (1992) Marketing Models. Prentice Hall, London.

[6] Zhang, W.T. (2002) Statistical Analysis of SPSS11 Tutorial (Advanced). Beijing Hope Electronic Press, Beijing, 192.

[7] Lin, Z.Y. (2007) Multivariate Analysis: SPSS Operation and Application. Peking University Press, Beijing, 186.

[8] Kaiser, H.F. (1974) An Index of Factorial Simplicity. Psychomertrika, 39, 13-36. http://dx.doi.org/10.1007/bf02291575

[9] Qiu, H.Z. and Lin, B.F. (2009) Theory and Application of Structural Equation Model. China Light Industry Press, Beijing, 88.

[10] Hou, J.T., Wen, Z.L. and Chen, Z.J. (2004) Structural Equation Model and Its Application. Education Science Press, Beijing. 
Submit or recommend next manuscript to SCIRP and we will provide best service for you:

Accepting pre-submission inquiries through Email, Facebook, LinkedIn, Twitter, etc. A wide selection of journals (inclusive of 9 subjects, more than 200 journals)

Providing 24-hour high-quality service

User-friendly online submission system

Fair and swift peer-review system

Efficient typesetting and proofreading procedure

Display of the result of downloads and visits, as well as the number of cited articles

Maximum dissemination of your research work

Submit your manuscript at: http://papersubmission.scirp.org/

Or contact jssm@scirp.org 